\title{
Comercialização socioeconômica de cucurbitáceas nas feiras livres de São Luís - MA
}

\author{
Socioeconomic commercialization of cucurbits at the street markets in São Luís - MA \\ Comercialización socioeconómica de cucurbitáceas nas feiras livres de São Luís - MA
}

Recebido: 02/05/2021 | Revisado: 11/05/2021 | Aceito: 11/05/2021 | Publicado: 27/05/2021

\author{
Adriely Sá Menezes do Nascimento \\ ORCID: https://orcid.org/0000-0002-2900-2646 \\ Universidade Estadual do Maranhão, Brasil \\ E-mail: adrielysa17@gmail.com \\ Fernanda Oliveira dos Santos \\ ORCID: https://orcid.org/0000-0002-7794-8735 \\ Universidade Estadual do Maranhão, Brasil \\ E-mail: nanda.veirantos1@gmail.com \\ Natália da Conceição Lima \\ ORCID: https://orcid.org/0000-0002-3793-6529 \\ Universidade Estadual do Maranhão, Brasil \\ E-mail: nathalyalc2011@gmail.com \\ Denise Maria Santos \\ ORCID: https://orcid.org/0000-0001-8886-6439 \\ Instituto Dom José de Educação e Cultura, Brasil \\ Universidade Veiga de Almeida, Brasil \\ E-mail: deniseufc@yahoo.com.br \\ Gabriela Gomes Ramos \\ ORCID: https://orcid.org/0000-0002-2028-1503 \\ Universidade Federal de Campina Grande, Brasil \\ E-mail: gabrielaagomees@gmail.com \\ Amanda de Lira Freitas \\ ORCID: https://orcid.org/0000-0002-5414-4873 \\ Universidade Federal Rural de Pernambuco, Brasil \\ E-mail: amanda.27.1ira@gmail.com \\ Maria José de Holanda Leite \\ ORCID: https://orcid.org/0000-0003-4154-3901 \\ Universidade Estadual do Maranhão, Brasil \\ E-mail: maryholanda@gmail.com
}

\begin{abstract}
Resumo
O objetivo da pesquisa foi caracterizar a comercialização das cucurbitáceas nas feiras livres de São Luís-MA, para fornecer informações sobre os atributos dessas hortaliças e as limitações na comercialização delas, e também traçar um perfil socioeconômico dos feirantes. A pesquisa foi realizada em cinco feiras livres situadas em cinco bairros da cidade (Cidade Operária, Cohab, João Paulo, Angelim e Mangueirão), a coleta de dados foi realizada por meio de questionários semiestruturados. A tabulação dos dados foi realizada no programa Microsoft Excel para análise e interpretação dos resultados. A partir dos resultados constatou-se que os homens têm mais participação (58\%) na venda de cucurbitáceas e as mulheres (42\%); em relação a renda $8 \%$ recebem menos que um salário mínimo por mês, $52 \%$ recebem até três salários e $10 \%$ mais que três salários. No que diz respeito a produção constatou-se que $65 \%$ não produzem as cucurbitáceas que comercializam, sendo $40 \%$ fornecidas por outros estados, apesar do Maranhão ser autossuficiente na produção da maioria das cucurbitáceas consumidas pela sua população. A presença mais marcante nas feiras foram Cucumis anguria L. e Cucumis sativus var. sativus L. Grande parte ficam expostas nas feiras em torno de 1 a 24 horas, após esse período quando não vendidas elas podem gerar perdas. Dentre os principais problemas na comercialização, o mais citado foi a concorrência que pode estar atrelada ao preço e a baixa variedade dos produtos. Observou que $48 \%$ dos feirantes possuem baixo conhecimento técnico. Sendo necessário investimentos em cursos básicos de comercialização para os feirantes afim de orientá-los na escolha das melhores estratégias de comercialização e romper essa limitação.
\end{abstract}


Palavras-chave: Curcubita sp; Feirante; Venda.

\begin{abstract}
The objective of the research was to characterize the commercialization of cucurbits in open markets in São Luís-MA, to provide information about the attributes of these vegetables and the limitations in their commercialization, and also to outline a socioeconomic profile of the marketers. The research was carried out in five open markets located in five neighborhoods of the city (Cidade Operária, Cohab, João Paulo, Angelim and Mangueirão), the data collection was carried out through semi-structured questionnaires. The data were tabulated using Microsoft Excel to analyze and interpret the results. From the results it was found that men have more participation $(58 \%)$ in the sale of cucurbits and women (42\%); in relation to income, $8 \%$ receive less than one minimum wage per month, $52 \%$ receive up to three wages and $10 \%$ more than three wages. With regard to production, it was found that $65 \%$ do not produce the cucurbits they sell, $40 \%$ being supplied by other states, despite Maranhão being self-sufficient in the production of most cucurbits consumed by its population. The most striking presence at the fairs were Cucumis anguria L. and Cucumis sativus var. sativus L. Most of them are exposed at fairs around 1 to 24 hours, after that period, when not sold, they can generate losses. Among the main problems in commercialization, the most cited was the competition that may be linked to the price and the low variety of products. He observed that $48 \%$ of marketers have low technical knowledge. It is necessary to invest in basic marketing courses for marketers in order to guide them in choosing the best marketing strategies and to break this limitation.
\end{abstract}

Keywords: Curcubite sp; Marketer; Sale.

\title{
Resumen
}

El objetivo de la investigación fue caracterizar la comercialización de cucurbitáceas en los mercados abiertos de São Luís-MA, brindar información sobre los atributos de estas hortalizas y las limitaciones en su comercialización, y también perfilar un perfil socioeconómico de los comercializadores. La investigación se realizó en cinco mercados abiertos ubicados en cinco barrios de la ciudad (Cidade Operária, Cohab, João Paulo, Angelim y Mangueirão), la recolección de datos se realizó mediante cuestionarios semiestructurados. Los datos se tabularon utilizando Microsoft Excel para analizar e interpretar los resultados. De los resultados se encontró que los hombres tienen más participación $(58 \%)$ en la venta de cucurbitáceas y las mujeres (42\%); en relación a los ingresos, el $8 \%$ recibe menos de un salario mínimo mensual, el 52\% recibe hasta tres salarios y el $10 \%$ más de tres salarios. En cuanto a la producción, se encontró que el $65 \%$ no produce las cucurbitáceas que comercializan, siendo el $40 \%$ abastecido por otros estados, a pesar de que Maranhão es autosuficiente en la producción de la mayoría de las cucurbitáceas consumidas por su población. Las presencias más destacadas en las ferias fueron Cucumis anguria L. y Cucumis sativus var. sativus L. La mayoría de ellos se exhiben en ferias alrededor de 1 a 24 horas, pasado ese período, cuando no se comercializan, pueden generar pérdidas. Entre los principales problemas en la comercialización, el más citado fue la competencia que puede estar vinculada al precio y la baja variedad de productos. Observó que el $48 \%$ de los comercializadores tienen un conocimiento técnico bajo. Es necesario invertir en cursos básicos de marketing para especialistas en marketing con el fin de orientarlos en la elección de las mejores estrategias de marketing y romper esta limitación.

Palavras clave: Curcubita sp; Comercializador; Venta.

\section{Introdução}

No Brasil, os produtos comercializados nas feiras livres são das mais variáveis possíveis, no entanto a venda de hortaliças recebe destaque pela a importância que desempenham na alimentação da população brasileira (BRANDÃO, 2012). As cucurbitáceas representam no contexto da horticultura uma parte significativa do volume comercializado de hortaliças. No Nordeste brasileiro a família Cucurbitaceae tem destaque no consumo e produção, devido a região apresentar uma grande diversidade climática o que favorece o desenvolvimento dessas hortaliças, no estado do Maranhã, uma vez que venda desses vegetais são bastante exploradas nas feiras livres (Queiroz, 1998; Duarte; Andrade Júnior, 2003).

Dentre a vasta gama de olerícolas consumidas mundialmente, a família Cucurbitaceae tem destaque, principalmente nas regiões tropicais. Ela representa um papel muito importante na produção de alimentos com boas qualidades nutricionais, além de ser rica em fibras (Amariz, 2011). Esta família é formada por cerca de 120 gêneros que contêm mais de 800 espécies, 
entre as quais se destacam o melão (Cucumis melo L.), melancia (Citrullus lanatus (thumb. Matsum \& Nakai), pepino (Cucumis sativus var. sativus L.) e abóbora (Cucurbita moschata L.) (Resende et al., 2013; Soares, 2014), as quais estão entre as primeiras espécies de plantas domesticadas no Velho e Novo Mundo (Bisognin, 2002), apresentam uma grande importância econômica para diversas regiões, devido à necessidade de mão-de-obra em seu cultivo, sendo em maior parte produzida pela agricultura familiar (Helden et al., 2007; Resende et al., 2013).

Nesse sentindo é importante destacar que, as cucurbitáceas são amplamente comercializadas em feiras, apesar de ser uma forma de comercialização antiga, as feiras livres ainda prevalecem em grande parte dos centros urbanos, sendo consideradas canais potencialmente mais eficientes pelo fato da relação direta entre o feirante e o consumidor possibilitar a diminuição dos custos de comercialização, além de favorecer uma aproximação e a troca de saberes entre os agricultores e consumidores (Martins et al., 2007; Brandão et al., 2015).

No Estado do Maranhão a comercialização de cucurbitáceas em feiras livres é uma atividade popular que colabora com a renda de várias pessoas, pois promove a geração de empregos diretos e indiretos, e demanda grande quantidade de mãode-obra, desde o cultivo até a comercialização (Resende et al., 2013). Esses produtos são amplamente vendidos in natura, alguns deles sendo muito utilizados na tradicional culinária do estado (Silva, 2014). Na cidade de São Luís, capital do Maranhão, as feiras livres estão distribuídas em toda a cidade e atraem consumidores de diversas localidades (Lima et al., 2014). Obstante a isso, com o aumento da população urbana, as feiras livres passaram a perder espaço pelo crescimento de outros canais de comercialização, como os supermercados que alcançaram um grande crescimento, pelo aumento e diversificação dos produtos e serviços ofertados, e também pela concorrência.

De maneira geral, pode-se dizer que o crescimento e desenvolvimento das feiras livres ainda é prejudicado pela falta de conhecimento, informação e recursos dos feirantes que, por não possuírem condições de promover suas vendas e atrair clientes, perdem espaço para grandes canais de comercialização. Porém, observa-se que, ainda hoje, as feiras desempenham um papel fundamental na consolidação econômica e social da agricultura familiar (Godoy et al., 2007; Coelho et al., 2009), além disso, a procura por cucurbitáceas comercializadas nas feiras livres ainda é considerada grande, dessa forma há uma necessidade de conhecer os atributos desses vegetais, assim como as limitações para a comercialização deles nas feiras da cidade sob a perspectiva dos feirantes.

Diante dessa realidade, o atual trabalho teve por objetivo caracterizar a comercialização de cucurbitáceas nas feiras livres de São Luís-MA, afim de conhecer as principais limitações para a comercialização desses vegetais, e também traçar um perfil socioeconômico dos comerciantes delas.

\section{Material e Métodos}

\subsection{Caracterização da área de estudo}

A pesquisa foi realizada na cidade de São Luís - Maranhão, localizada na região nordeste, com coordenadas de $2^{\circ} 31^{\prime}$ 48" S 44 18' 10" 0, em cinco feiras livres situadas em bairros da capital (Cidade Operária, João Paulo, Cohab, Angelim e Mangueirão) (Figura 1). 
Figura 1. Localidade das feiras no munícipio de São Luís - MA, dando ênfase nas feiras analisadas.

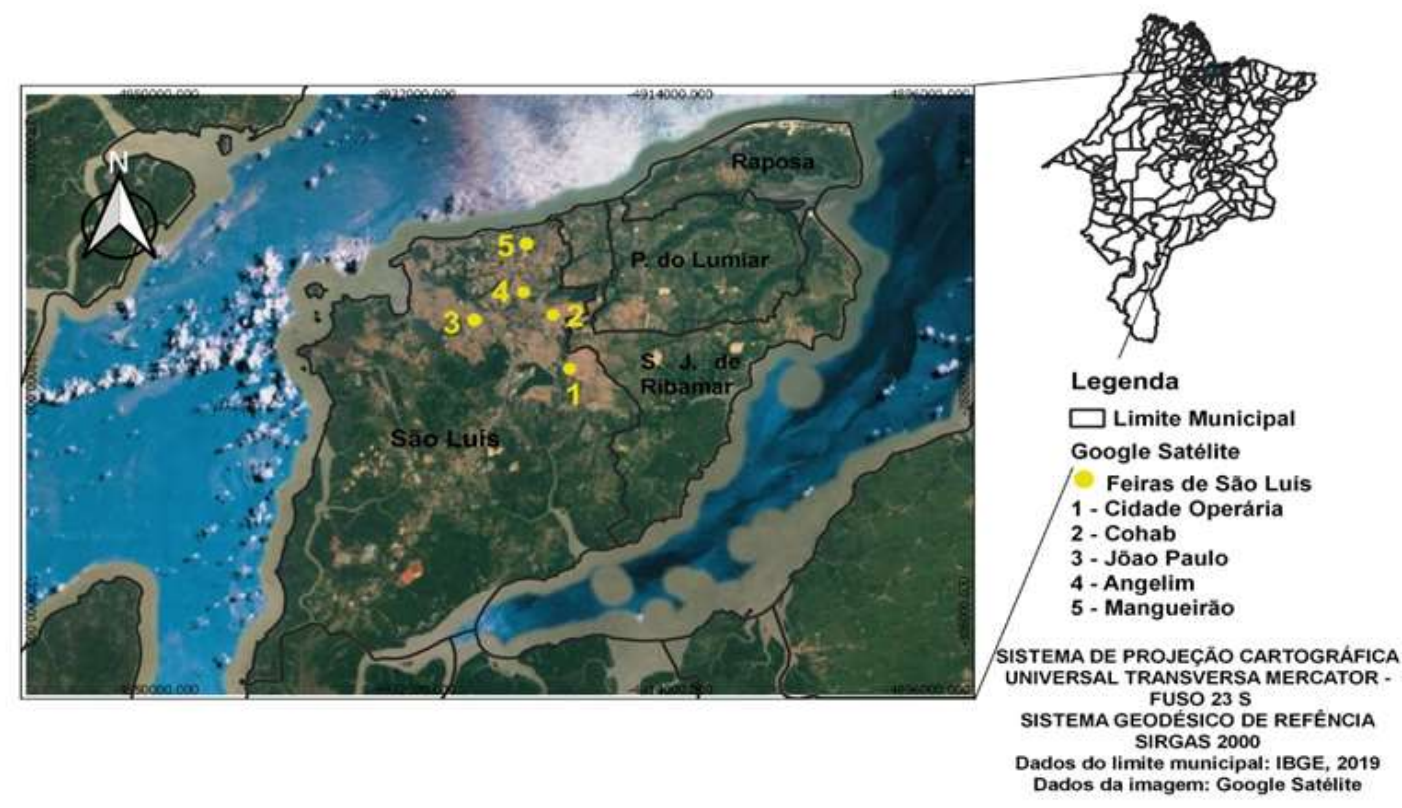

Fonte: Autores.

\subsection{Etapas para realização da pesquisa}

Para compreender a dinâmica da comercialização nas feiras livres da capital, foi utilizada no processo de investigação a metodologia qualitativa. A técnica de coleta de dados é importante para que os resultados alcancem os objetivos esperados (Gil, 2010). A pesquisa qualitativa, por sua vez, tem a capacidade de gerar informações mais ricas e detalhadas sobre um grupo menor de pessoas e de casos. Sendo assim, como forma de coleta de dados, optou-se pela aplicação de questionários semiestruturados. Nesse trabalho a aplicação de questionário foi destinada exclusivamente a feirantes que comercializam cucurbitáceas nas feiras livres da cidade de São Luís, a fim de fornecer informações pertinentes para caracterizar a comercialização desse grupo de plantas, uma vez que as cucurbitáceas representam grande importância no estado por fazer parte da tradicional culinária maranhense.

A abordagem foi feita de forma tradicional, ou seja, por meio de comunicação direta com o feirante, sendo o questionário dividido em duas seções, a primeira composta por perguntas direcionada ao perfil social, econômico e educativo dos entrevistados, que envolvia perguntas sobre: Nome do feirante; Gênero; Faixa etária; Renda; Nível de escolaridade. A segunda seção envolvia perguntas voltadas à comercialização das cucurbitáceas em si, tais como: As cucurbitáceas mais vendidas, se é o próprio feirante que produz as cucurbitáceas? origem delas; Tempo de exposição; tem muitas perdas póscolheita? os principais problemas enfrentados para comercialização de cucurbitáceas; os principais clientes e se o feirante possui conhecimento técnico de produção e comercialização? As entrevistas foram realizadas entre 23/01/2020 a 30/01/2020 nas feiras livres de São Luís. Onde foram entrevistados 12 vendedores por feira, totalizando 60 questionários.

Devido ao pequeno número de pesquisas com essa família de plantas no estado, esse trabalho irá promover conhecimento acerca, tanto do mercado de cucurbitáceas no Maranhão como também com o perfil de seus respectivos vendedores, afim de conhecer os desafios, e que soluções poderiam ser tomadas para a melhoria do comércio das mesmas, proporcionando assim suporte para trabalhos futuros.

A pesquisa qualitativa realizada por meio de questionários é uma metodologia de caráter exploratório, ela é mais importante que a análise estatística quando não se tem uma hipótese definida e o objetivo é explorar o comportamento de um 
determinado indivíduo, como ocorre nesta pesquisa, visto que se deseja conhecer o comportamento e as particularidades do feirante em função da comercialização de cucurbitáceas.

\subsection{Análise dos Dados}

Inicialmente os dados coletados foram tabulados no programa Microsoft Excel para análise e construção das figuras. Dessa forma, permitiu-se melhor interpretação dos resultados e facilidade na comparação dos dados.

\section{Resultados e Discussão}

Em relação ao gênero dos feirantes entrevistados nas cinco feiras, $42 \%$ são mulheres e $58 \%$ são homens (Figura 2). Fato este que pode estar associado a repressão e associação do trabalho feminino, apenas ao trabalho doméstico durante muito tempo. De acordo com Confort et al. (2016); Silva et al. (2014), a porcentagem do gênero masculino, e com idade entre 40 e 60 anos, pode ser visto como um padrão nessa profissão de feirante. Outra questão é retratada por Marion; Bonna, (2016); Cotrim (2014), que destaca a desvalorização das tarefas desempenhadas pelas mulheres, mas que não estão diretamente relacionadas com a geração de renda, e sim com algumas regras de dominação de gênero (homens fazem trabalhos que exigem forças, e mulheres desempenham trabalhos domésticos). Esses pensamentos se reproduzem nas várias esferas da atividade social. Mesmo que esse trabalho não apresente uma diferença tão significativa, é notório a divisão ainda existente entre trabalho masculino e feminino. A pesquisa ainda abrangeu diferentes faixas etárias entre homens e mulheres, com predomínio da variação de idade entre 20 à 40 anos no que se refere 43\%, e 41 à 55 anos que corresponde a 32\% (Figura 3). Esses dados podem ser explicados pelo fato da grande parcela ser casada e com filhos, ou seja, necessitar de uma renda fixa mensal, ou pelas fortes pressões do mercado de trabalho que se torna cada vez mais seletivo em relação à idade.

Figura 2. Gênero dos feirantes que comercializam cucurbitáceas.

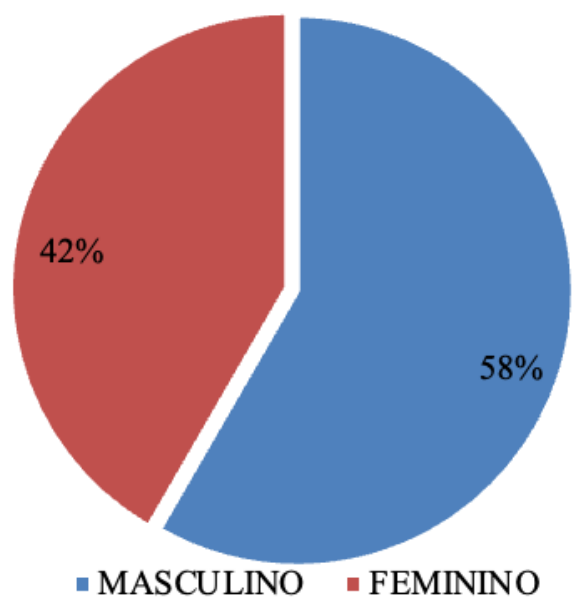

Figura 3. Faixa etária dos feirantes que comercializam cucurbitáceas (em anos).

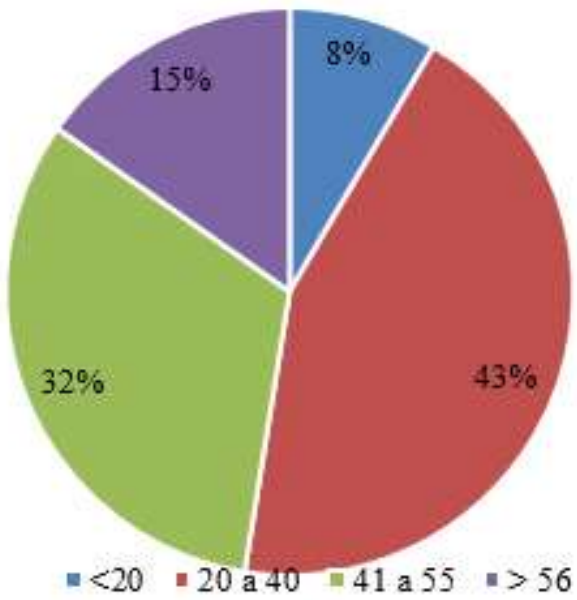

Fonte: Autores.

Ao analisar a renda mensal desses feirantes, verificou-se que $8 \%$ recebem menos que um salário mínimo por mês, $52 \%$ compreendem valores mensais correspondentes até três salários mínimos, $10 \%$ recebem mais que três salários mínimos, ou seja, os feirantes com maiores níveis de escolaridade, apresentaram maiores porcentagens de renda mensal (Figura 4). Porém, essa diferenciação de porcentagem pode também estar relacionada com a localização das feiras que estão situadas em 
diferentes bairros da cidade, e abrangem um público consumidor bastante diversificado, como a feira da Cohab e João Paulo que durante a entrevista, foi observado uma renda mensal maior, em detrimento das outras feiras, outra razão estar ligada com alguns atributos individuais de cada feirante como, bom atendimento, preço competitivo, variedade (comercialização de outros produtos, além das cucurbitáceas) e qualidade dos produtos. Estes são alguns dos atrativos aos clientes, conforme verificado no estudo de Alves et al. (2014), sobre a satisfação dos consumidores de hortifrutícolas. E 30\% não quiseram ou não souberam responder, em razão da feira livre não ser uma forma de renda complementar a principal renda. Pode-se citar como exemplo a presença de alguns aposentados, pedreiros e lojistas que por considerarem sua renda baixa, procuram complementação de renda nas feiras.

Figura 4. Percentual da renda dos feirantes (em R \$/ano).

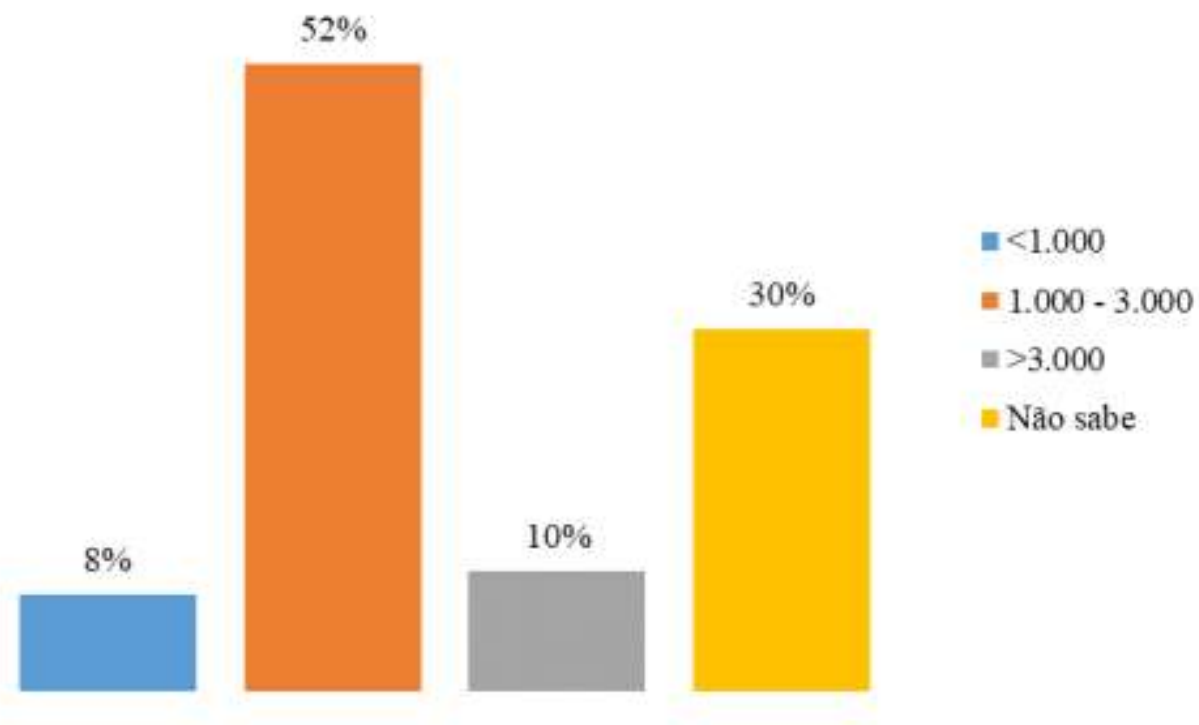

Fonte: Autores.

Os dados do grau de escolaridade dos feirantes, mostram que $13 \%$ possuem fundamental incompleto, $27 \%$ somente o fundamental, $17 \%$ ensino médio incompleto. Esse fato ocorre em razão da maioria dos feirantes trabalharem desde cedo para auxiliar na renda da família, implicando assim, na desistência dos estudos por não haver outras alternativas, e $42 \%$ apresenta o segundo grau do ensino médio, e apenas $2 \%$ possuem ensino superior. Esses dados evidencia o baixo grau de escolaridade desses feirantes (Figura 5). Resultados semelhantes foram encontrados por Rocha et al. (2009) com feirantes da feira de Passo fundo (RS), em que o grau de escolaridade mais comum entre os feirantes foi o fundamental. E também por Campos et al. (2017) na feira de Juiz de Fora (MG), que 48\% apresentaram segundo grau completo. Em ambos trabalhos não houve registro de feirantes com nível de pós-graduação. Essa abordagem se faz necessária, pois segundo Sousa Filho; Bomfim, (2013), quanto maiores os níveis de escolaridade, consequentemente maior é a possibilidade de os feirantes ampliarem seus conhecimentos, capacidade de gestão a favor da comercialização dos produtos, e maior obtenção de lucro. 
Figura 5. Nível de escolaridade dos feirantes.

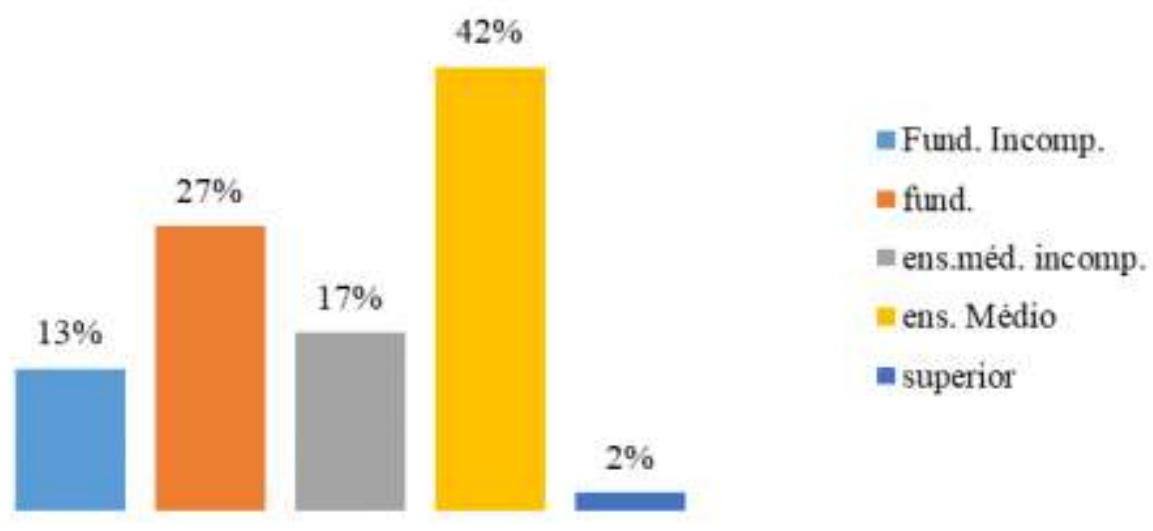

Fonte: Autores.

Dentre os feirantes entrevistados, 65\% não produzem as cucurbitáceas comercializadas (Figura 6), sendo $40 \%$ fornecidas por outros estados (Figura 7) através do centro estadual de abastecimento de São Luís - Ceasa - MA. Apenas 3\% dos feirantes produzem o que comercializam, impactando na quantidade de cucurbitáceas produzidas na cidade (29\%).

Figura 6. Porcentagem de produção do próprio feirante.

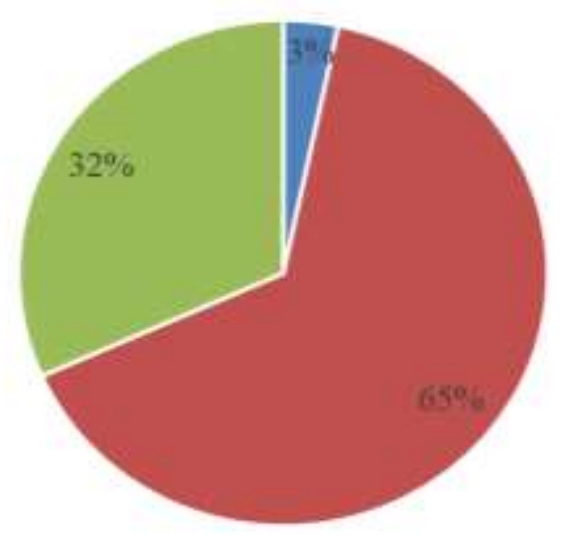

$=$ SIM = NÃO = SIM, EM PARTE
Figura 7. Origem das Cucurbitáceas comercializadas na feira.

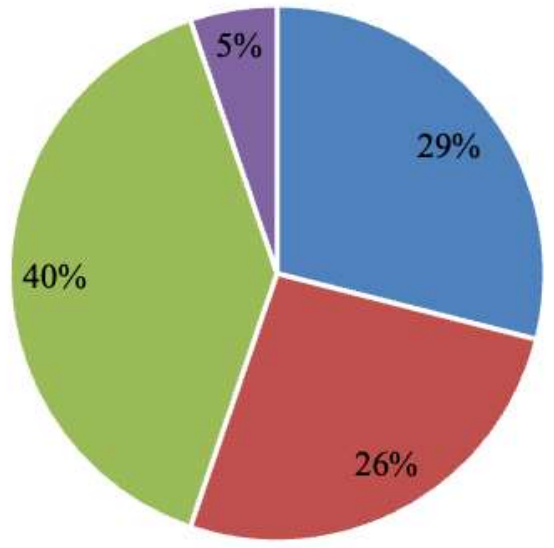

$\begin{array}{ll}\text { - Própria cidade } & \text { = cidade vizinha } \\ \text { = outro estado } & \text { " não sabe }\end{array}$

Fonte: Autores.

Conforme um diagnóstico de horticultura feito pelo Sebrae (2009), o Maranhão poderia ser autossuficiente na produção da maioria das hortaliças consumidas pela sua população, assim como gerar excedentes para comercializar em outros estados. Todavia, observa-se que em há elevado fluxo de produtos oriundos de outros estados, geralmente escoados a longas distâncias. Portanto, imagina-se que esteja havendo aumento da susceptibilidade a perdas quantitativas e qualitativas, bem como incremento nos preços finais. O que pode limitar a continuidade dos comerciantes na atividade e o acesso dos consumidores a produtos com boa qualidade e preços justos, notadamente cucurbitáceas). 
O município de São Luís oferece condições edafoclimáticas favoráveis para o cultivo de hortaliças, frutas, plantas medicinais, entre outras culturas. Contudo, a quantidade de áreas produtoras não se traduz em garantia do mínimo satisfatória no abastecimento alimentar interno. Logo, o estudo refletiu a necessidade da expansão da produção desses alimentos na cidade, e por meio disso a obtenção de maior conhecimento e lucratividade ao feirante e um menor preço ao consumidor final.

Dentre as cucurbitáceas comercializadas, o maxixe (22\%) destacou-se como uma das cucurbitáceas mais comercializadas nas feiras estudadas na ilha de São luís. Através disto, pode-se inferir que o destaque na comercialização dessa hortaliça deve-se a sua pouca exigência, onde alguns olericultores não necessitam realizar a fertilização, isso porque ele se beneficia de resíduos de nutrientes que outrora já foram aplicados, porém quando trata-se de um de baixa fertilidade natural, faz-se necessário o uso de fertilizantes. O maxixe também possui um ciclo que varia de 55 a 70 dias, sendo bem adaptado a diversos tipos de solos, exceto em condições de $\mathrm{pH}$ muito ácido. Ainda, as condições climáticas de São luís tornam o processo de produção mais facilitado o tornando um produto de grande concorrência nas feiras da capital.

Outra hortaliça que apresentou destaque foi o pepino (21\%) uma Cucurbitácea bastante apreciada pela população, o que torna sua presença nas feiras indispensável. Mesmo sendo bastante requerida, a maior parte dos feirantes entrevistados não o produzem, logo, infere-se que seja em consequência do manejo mais tecnológico no qual o pepineiro exige (cultivo protegido), o que acaba por inviabilizar a produção dos feirantes, tanto pela ausência de conhecimento técnico como de recursos para investimento.

O melão $(7 \%)$ foi a cucurbitácea com menor expressão nas feiras estudadas. Por trata-se de uma cultura bastante exigente em luminosidade, umidade do ar e do solo e boas práticas edáficas, os feirantes optam por comprar em fornecedores de outros estados através da Ceasa.

Figura 8. Principais cucurbitáceas comercializadas. A - Maxixe e abóbora, B - Melão, C - Melancia e D - Pepino.
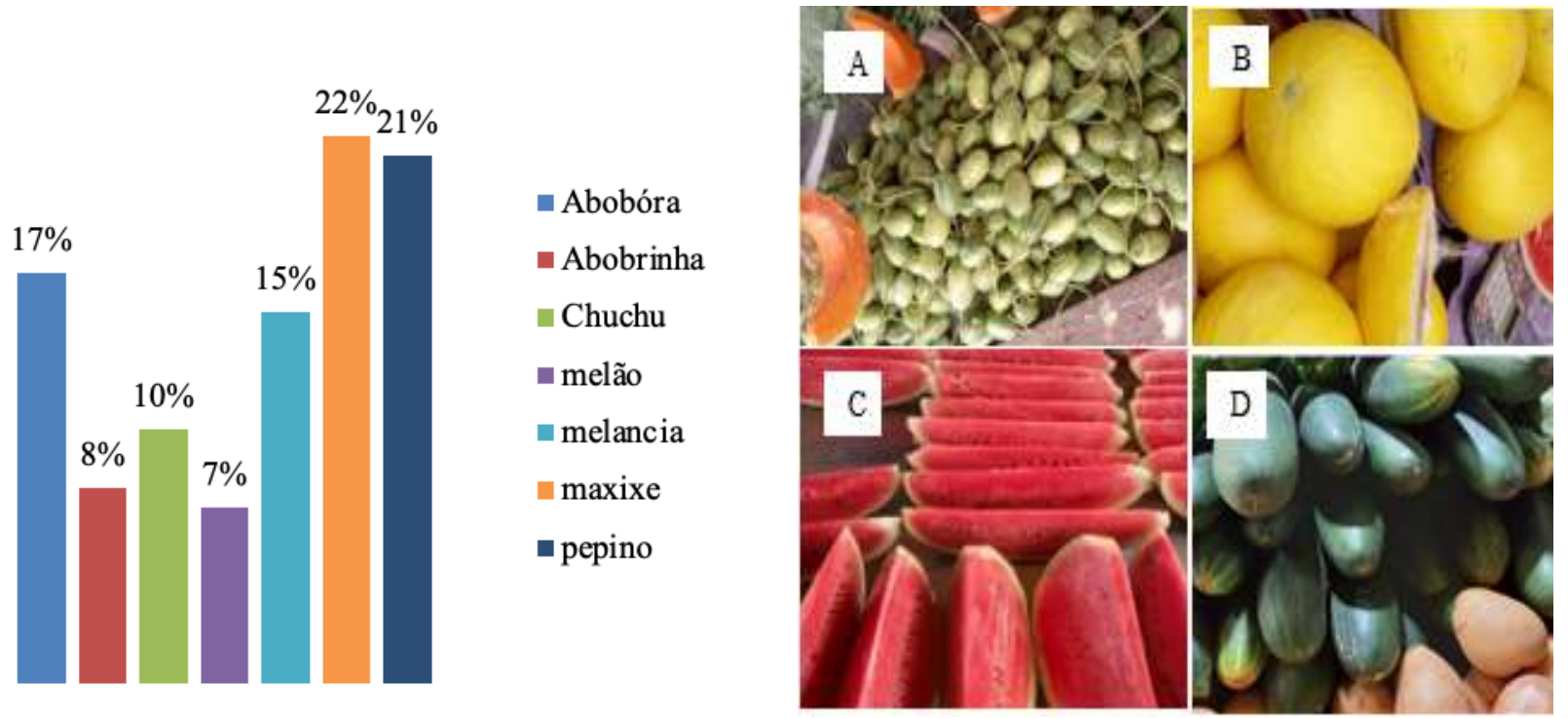

Fonte: Autores.

Com base nos dados $62 \%$ das cucurbitáceas passam entre 1 a 24 horas expostas na feira, quando não vendidas são conservadas e posteriormente expostas novamente, contabilizando mais de 24 horas em exposição, dessa forma, 33\% delas foram relatadas que passam entre 25 a 48 horas, e apenas $5 \%$ passam mais de 48 horas expostas (Figura 9), segundo os feirantes inclui-se nessa última categoria principalmente o chuchu, abobrinha e 
pepino, isso quando não tem muita saída desses produtos, já cucurbitáceas como melancias e abóboras não chegam durar nem 24 horas expostas, visto que são majoritariamente comercializadas cortadas e após esse processo quando não vendidas, reduz o tempo de exposição, e intensifica as perdas pós-colheita.

Figura 9. Tempo de exposição das Cucurbitáceas comercializadas na feira.

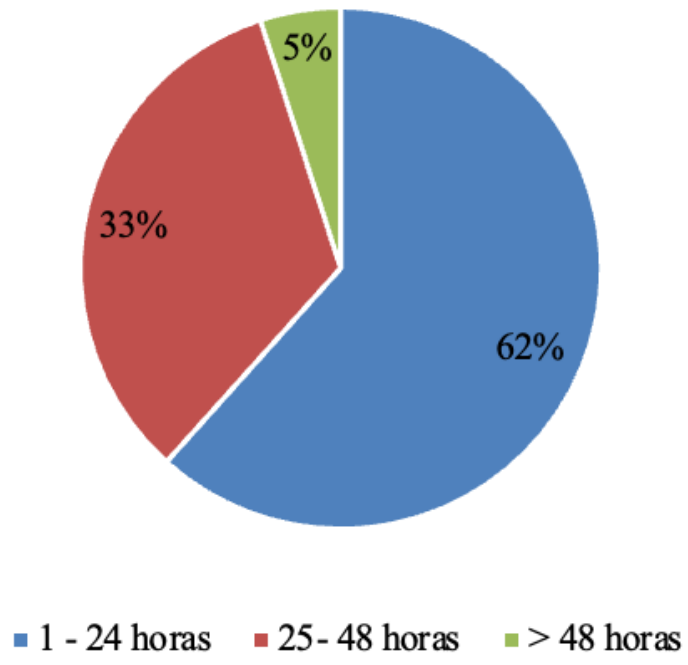

Fonte: Autores.

O maxixe também é uma das cucurbitáceas que dura pouco tempo de exposição, pelo fato dos frutos terem um curto período pós-colheita até se tornarem amarelecidos e ficarem sem valor comercial, estando esse fato associado à sua colheita desuniforme (Silva et al., 2015; Silva, 2016), o armazenamento em baixas temperaturas pode retardar essa situação, dessa forma muitos dos feirantes comentaram que armazenam os maxixes não vendidos e com boas características em geladeiras, o que influencia na redução das perdas-pós colheita e aumenta o tempo de prateleira.

Com relação às perdas pós-colheita, $77 \%$ dos feirantes responderam que há bastante perda na comercialização de cucurbitáceas, 23\% dos feirantes responderam que não há tantas perdas, que varia de acordo com a demanda dos consumidores (Figura 10). Essas perdas estão ligadas basicamente a qualidade das cucurbitáceas, logo o ambiente em que se encontram está sujeito a várias interferências climáticas que não favorece a preservação da qualidade do pronto, de acordo com Álvares (2006) a temperatura é um dos fatores mais importante para a manutenção da qualidade dos produtos hortícolas após a colheita, pois a perda da qualidade observada nos vegetais após serem colhidos ocorre devido processos fisiológicos e bioquímicos, que são influenciados primariamente pela temperatura do produto. 
Figura 10. Perdas pós colheita das Cucurbitáceas comercializadas e registro de perda de abóbora.
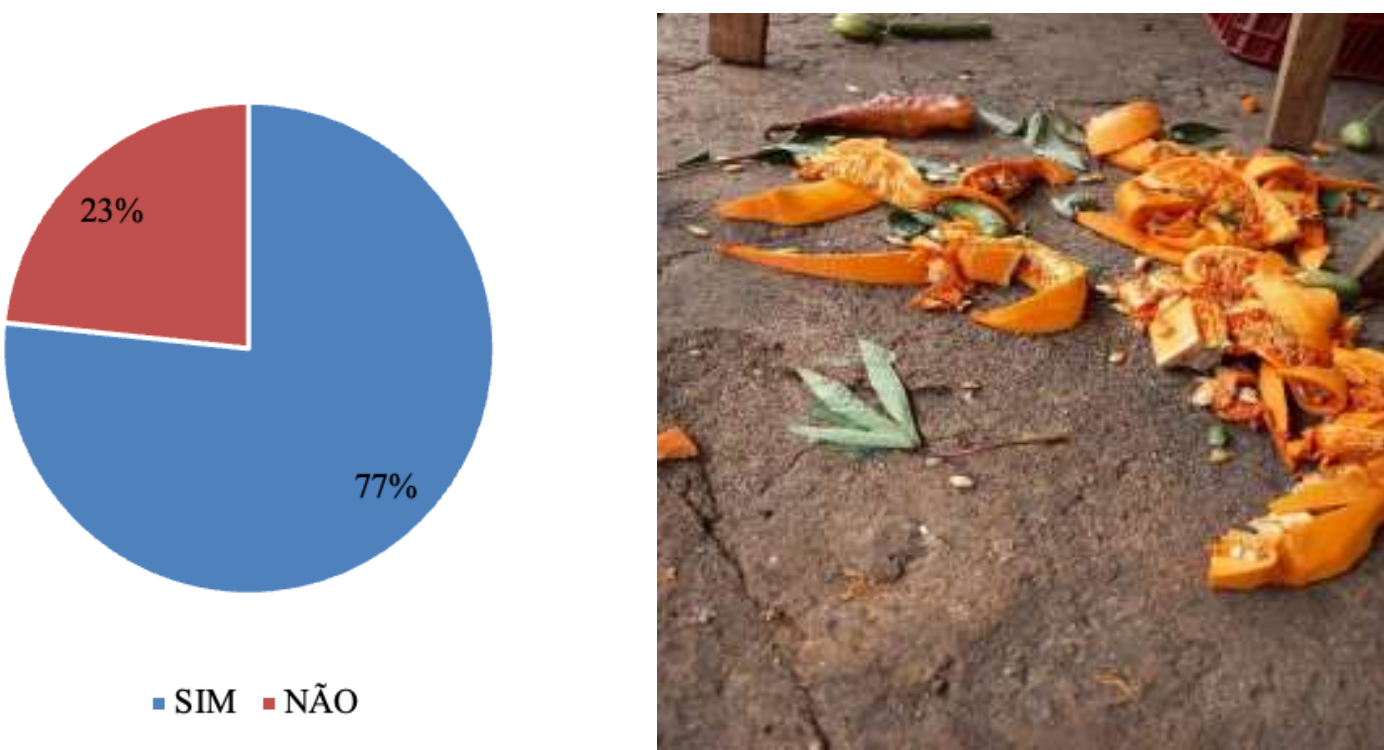

Fonte: Autores.

Ao questionar os feirantes sobre sua percepção em relação aos principais problemas enfrentados para a comercialização das cucurbitáceas nas feiras, verificou-se que a maioria apontou a concorrência (30\%) como a principal limitação em relação aos outros 6 problemas (Figura 11), uma vez que a concorrência ocorre tanto dentro quanto fora das feiras. Segundo Brandão et al. (2015) os grandes concorrentes das feiras livres na venda de produtos de hortifruticultura (grupo em que se encontram as cucurbitáceas) são os supermercados e sacolões/varejões.

A causa da alta concorrência pode estar atrelada a vários fatores, de acordo com Silveira et al. (2017) os principais a serem analisados são o preço, a qualidade dos produtos, a disponibilidades nos pontos de venda e a imagem que eles transmitem ao consumidor. A concorrência também pode estar ligada a ausência de conhecimento sobre as estratégias de comercialização, logo essa pesquisa apontou que grande parte dos feirantes (48\%) têm um baixo conhecimento técnico de comercialização, $40 \%$ têm um conhecimento médio e 12\% alto, (Figura 12), o que pode estar influenciando na concorrência, uma vez que o feirante fica limitado de aumentar suas vendas por não conhecer a dinâmica do mercado e saber agregar valor aos seus produtos.

Foi observado que $22 \%$ dos entrevistados apontaram a Infraestrutura das feiras também como uma das limitações para a comercialização, Hino Júnior et al. (2017) afirma que a deficiência na infraestrutura das feiras apresenta-se como um obstáculo ao desenvolvimento de um gerenciamento eficiente, $9 \%$ dos entrevistados apontaram a organização das feiras, entre os quais se destacam a forma como estão distribuídas as bancas, 13\% apontaram os problemas sanitários, dentro dessa categoria foi relatado pelos feirantes principalmente a ausência de banheiros sanitários e o tratamento de esgoto; e $6 \%$ a segurança, foi observada nessa categoria que feirantes da feira do Mangueirão foram os que mais contribuíram para esse dado, uma vez que eles relataram muito a questão da feira situar-se no mesmo espaço do tráfego de veículos, o que impede segurança de feirantes e consumidores.

Figura 11. Problemas enfrentados na feira e na

Figura 12. Conhecimento Técnico dos feirantes. 
comercialização de cucurbitáceas.

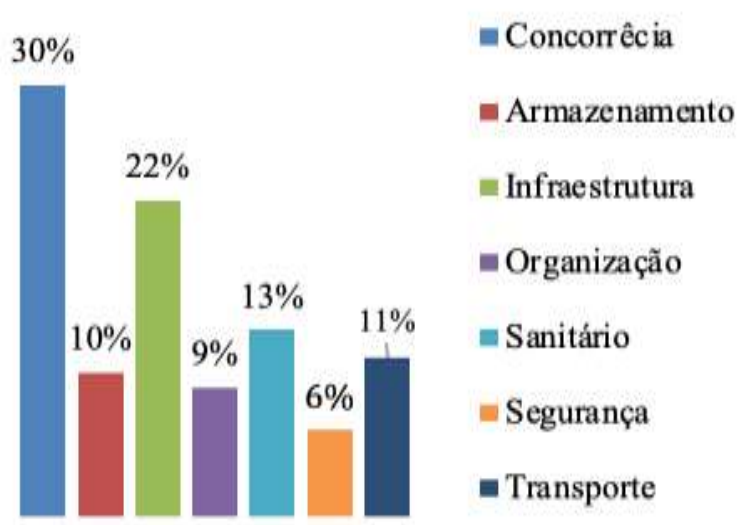

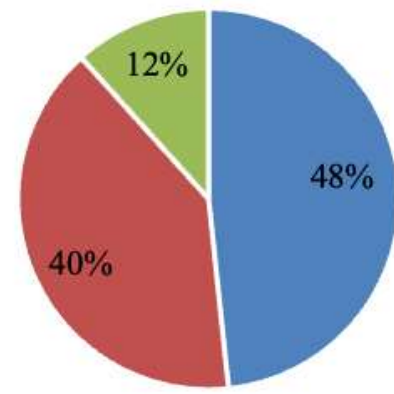

- BAIXO - MÉDIO -ALTO

Fonte: Autores.

Segundo Cordeiro et al., (2008), os principais problemas enfrentados pela horticultura estão relacionados à alta perecibilidade dos produtos, fazendo com que o tempo entre a colheita e a entrega seja pequena, Jacobi et al. (2000) afirmam que para prolongar a vida útil desses produtos as técnicas de armazenamento são imprescindíveis, nessa pesquisa $10 \%$ dos feirantes apontaram problemas no armazenamento das cucurbitáceas, o que pode estar influenciando na redução da vida útil desses vegetais e aumentando as perdas. $11 \%$ dos entrevistados expuseram que possuem dificuldades no transporte dos vegetais, onde alguns nem mesmo possuem meio de locomoção próprio, o que acaba limitando a comercialização.

As feiras de São Luís apresentam diversas deficiências estruturais, muitas delas de fácil resolução, onde só seriam necessárias ações da prefeitura da cidade. Porém, há problemas que englobam um âmbito maior, como a produção de cucurbitáceas na capital no qual possui um grande potencial produtivo, porém pouco explorado. Tais ações necessitam de um forte incentivo para que possam ser realizadas, tanto do governo quanto de produtores dispostos a adquirir conhecimento acerca de tal produção, isso não proporcionaria bons resultados apenas aos produtores, mais também aos consumidores, através da diminuição do preço final desses produtos.

\section{Conclusão}

A comercialização de cucurbitáceas nas feiras livres de São Luís é feita por feirantes, que no geral não tem um padrão, no entanto a grande parcela são pessoas com idade média de 30 anos, com ensino médio e que obtém da feira uma renda média de $\mathrm{R} \$ 2.000$ com a venda de cucurbitáceas e o incremento de outros vegetais.

As cucurbitáceas em sua maioria não são produzidas no município de São Luís, algumas são de outros municípios e grande parte são de outros estados havendo necessidade de investimentos e incentivos na produção dessas hortaliças no estado, pois este apresenta condições favoráveis ao desenvolvimento delas.

No processo de comercialização de cucurbitáceas a concorrência é a principal limitação apontada pelos feirantes, devido o preço igualitário e a inexistência de variedade dos produtos, o baixo conhecimento de comercialização pelos feirantes também influência nesse problema. Portanto, é necessários investimentos em cursos básicos de comercialização para os feirantes afim de romper esse cenário e orientá-los na escolha das melhores estratégias de comercialização, fundamentadas em conhecimentos técnicos.

\section{Referências}

Álvares, V.S. Pré-resfriamento, embalagem e hidratação pós-colheita de salsinha. Dissertação (Doutorado em Fitotecnia). Viçosa, MG, 2006. 161p. 
Alves, R. J. M., Souza, L. P. F., \& Pontes, A. N. Perfil socioeconômico e satisfação dos consumidores de produtos hortifrutícolas do Complexo do Ver-o-Peso, Pará. Enciclopédia Biosfera, Goiânia, v. 10, n.19, p. 2912-2920, 2014

Amariz, A. Qualidade, compostos bioativos e atividade antioxidante de frutos de Jerimum de leite (Cucurbita moschata) pertencentes ao banco ativo de Germoplasma de cucurbitáceas da Embrapa Semiárido. Dissertação (mestrado em Fitotecnia). Universidade Federal Rural do Semiárido, p. 135 , 2011.

Bisognin, D. A. Origin and evolution of cultivated Cucurbis, Ciência Rural, Santa Maria, v.32, n.5, p.715-723, 2002.

Brandão, A. A. Produção e comercialização de hortaliças em feiras livres na microrregião de Januária. (Dissertação). Dissertação em ciências agrárias. Universidade Federal de Minas Gerais, 2012.

Brandão, A. A. et al. Perfil socioeconômico dos consumidores de hortaliças em feiras livres na microrregião de Januária. Horticultura Brasileira, v. 33, n. 1, p. $119-124,2015$

Campos, I. C. R. et al. Perfil e percepções dos feirantes em relação ao trabalho e segurança alimentar e nutricional nas feiras HU Revista, Juiz de Fora, v. 43, n. 2 , p. $247-254,2017$

Coelho, J. D.; \& Pinheiro, J. C. V. Grau de organização entre os feirantes e problemas por eles enfrentados nas feiras livres de Cascavel e de Ocara, no Ceará. In: Congresso de economia e sociologia rural - SOBER, 47, 2009.

Confort, A. M. A. S. et al. Perfil Socioeconômico de Agricultores Familiares do Município de Muniz Freire, Espírito Santo. Revista Guará, v. 1, n. 5, p. 119128, jun. 2016.

Cordeiro, K. W. et al. A comercialização de hortaliças sob a ótica da economia dos custos de transação. XXVIII Encontro nacional de engenharia de produção, Rio de Janeiro - RJ. 2008.

Cotrim, D. (Org.). Desenvolvimento rural e agricultura familiar: produção acadêmica da Ascar. Porto Alegre, RS: Emater/RS-Ascar, 2014. (Coleção Desenvolvimento Rural, v. 3). 2014.

Duarte, R. L. R.; Andrade Júnior, A. S. de. Estudo da oferta e comercialização de melão na Ceasa-PI (1991-1996). Horticultura Brasileira, v. 21, n. 1, p. 127$131,2003$.

Gil, A. C. Como elaborar projetos de pesquisa. 5. ed. São Paulo: Atlas, 2010. 184 p

Godoy, W.I.; Anjos, F.S. O perfil dos feirantes ecológicos de Pelotas-RS. Revista Brasileira de Agroecologia, v.2, n.1, fev. 2007.

Helden, G.; Neitzke, R.; \& Barbieri, R. L. Chave para a identificação das espécies de abóboras (Cucurbita, Cucurbitaceae) cultivadas no Brasil. Embrapa Clima Temperado. Pelotas, documento 197. $1^{\text {a }}$ ed. p. 31, 2007.

Hino Junior, J. R, Pasche, A., Jordan, E. N., \& Cubas, S. A. III-390-gerenciamento de resíduos sólidos orgânicos de feiras-estudo de caso: secretaria municipal de abastecimento do município de curitiba. Congresso Abes, 2017.

Jacobi, K. K; Macrae, E. A.; \& Hetherington, S. E. Effectsof hot airconditioningof 'Kensington' mango fruitonthe response to hot watertreatment, PostharvestBiologyand Technology, EUA, v.21 p.39-49, 2000.

Lima, D. B; Moraes, D. A. R; \& Silva, J. S. Um olhar sobre as feiras de São Luís: uma visão a partir do contexto socio econômico da Feira da Cidade Operária. Anais. VII Congresso brasileiro de geógrafos. 2014.

Marion, A. A.; \& Bona, A. N. A importância da mulher na agricultura familiar. Curso de Cooperativismo Solidário e Crédito Rural. Publica Cresol. Francisco Beltrão, p. 1-11, 2016.

Martins, V.A.; Margarido, M.A.; \& Bueno, C.R.F. Alteração no perfil de compra de frutas, legumes e verduras nos supermercados e feiras livres na cidade de São Paulo. Informações Econômicas, São Paulo, v.37, n.2, p.1-8, 2007.

Queiroz, M. A. cucurbitáceas no semiárido do nordeste brasileiro: resgate, conservação e uso. CPATSA/EMBRAPA. Petrolina, PE, 1998.

Resende, G. M; Borges, R. M. E; \& Gonçalves, N. P. Abóbora em diferentes densidades de plantio no Vale do São Francisco. Horticultura Brasileira vol.31, n.3, Vitoria da Conquista. 2013

Resende, G. M; Borges, R. M. E; \& Gonçalves, N. P. S. Produtividade da cultura da abóbora em diferentes densidades de plantio no Vale do São Francisco. Horticultura Brasileira, v. 31, p. 504-508, 2013.

Rocha, C. H. et al. Perfil socioeconômico dos feirantes e consumidores da feira do produtor de Passo Fundo, RS. Ciência Rural, v. 40, n. 12, p. 2593-2597, dez. 2010.

SEBRAE. Horticultura - Desperdício de Alimentos é preocupação mundial, 2011. <http://www.sebrae.com.br/setor/horticultura>.

Sousa, A. N. S. et al. Perdas pós-colheita de hortaliças no mercado varejista de Chapadinha, Maranhão, Brasil. Revista Agrotrópica, v. 30, p. $127-134,2018$.

Silva, A. L. B. Culinária maranhense: A identidade alimentar na capital do Maranhão sob o olhar dos frequentadores das áreas turísticas. Dissertação (mestrado em Cultura e sociedade). Universidade Federal do Maranhão - UFMA, 115 p, 2014.

Silva, F. C. et al. Action of Potassium Permanganate on the Shelf-Life of Cucumis anguria Fruit. Acta Horticulturae, v. 1071, p. 105-111, 2015.

Silva, F. C. Crescimento e alterações fisiológicas pós-colheita em frutos de maxixe (Cucumis anguria). Tese (Doutorado) - Viçosa, MG, 2016. 
Research, Society and Development, v. 10, n. 6, e20010615687, 2021

(CC BY 4.0) | ISSN 2525-3409 | DOI: http://dx.doi.org/10.33448/rsd-v10i6.15687

Silveira, V. C. et al. Avaliação da importância das feiras livres e a forma de comercialização adotada pelos feirantes na cidade de Nova Andradina - MS. Encontro Internacional de Gestão, Desenvolvimento e Inovação (EIGEDIN), v. 1, n. 1, 2017.

Sousa Filho, H. M. S.; \& Bonfim, R. M. Oportunidades e desafios para a inserção de pequenos produtores em mercados modernos. In: centro de gestão e estudos estratégicos (CGEE). A pequena produção rural e as tendências do desenvolvimento agrário brasileiro: ganhar tempo é possível? Brasília: CGEE, 2013, cap. 3, p. 71-100. 2013 